\title{
ESPIRITUALIDAD DEL SACERDOTE DIOCESANO SECULAR (I)
}

DOI: https://doi.org/10.52039/seminarios.v51i175.734

Autor: Florentino Muñoz. Profesor de Teología en el Seminario Mayor de Cáceres y Vicario Episcopal para el Clero de la diócesis de CoriaCáceres.
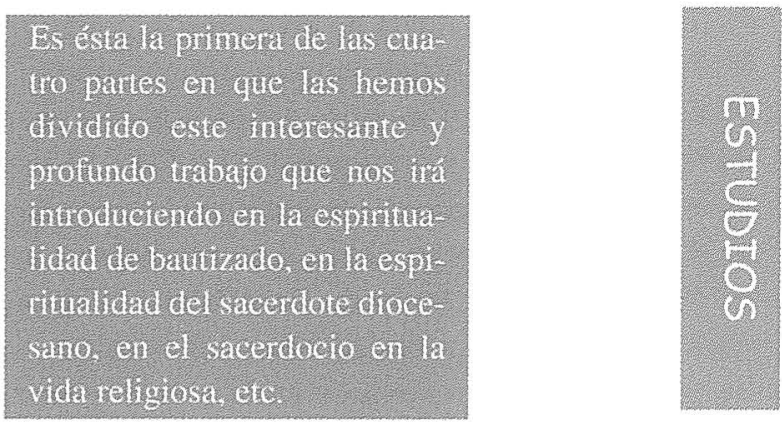

\section{INTRODUCCIÓN}

La inmensa mayoría de los sacerdotes realizan su ministerio con un esfuerzo gozoso, frecuentemente fruto de un heroísmo silencioso. Trabajan hasta el límite de sus propias energías, sin ver, a veces, los frutos de su labor. Con todo, hemos de decir también que, en nuestros días, el sacerdote experimenta dificultades en el ejercicio de su ministerio pastoral ${ }^{1}$.

Para superar estas dificultades y problemas "el presbítero dará la primacía absoluta a la vida espiritual, al estar siempre con Cristo y a vivir con generosidad la caridad pastoral, intensificando la comunión con todos y, en primer lugar, con los otros sacerdotes".

${ }^{1}$ SCC: "el sacerdote sufre con frecuencia la fatiga, la desconfianza, el aislamiento y la soledad" (Directorio para el Ministerio y vida de los presbíteros, 37). 
Por eso, es necesario fomentar y favorecer la "espiritualidad del Sacerdote diocesano secular". Urge profundizar cada día más en la verdadera experiencia de Dios y traducirla en una gran coherencia de vida sacerdotal ${ }^{2}$. La maduración espiritual es para los sacerdotes una gozosa posibilidad y una rigurosa exigencia. Este crecimiento es tarea para toda la vida (cf. PDV 70), pues un sacerdote evangélicamente anémico o estancado contradice su propia condición espiritual y pastoral. Volvamos a nuestros orígenes, entremos dentro de nosotros y redescubramos el misterio de nuestra vocación sacerdotal ${ }^{3}$. El Sacerdote ha de ser un hombre con una profunda experiencia de Dios desde la que viva, hable, actúe 4 .

Los Presbíteros, contemplando el rostro crucificado y glorioso de Jesucristo y testimoniando el amor del Buen Pastor en la Iglesia y en el mundo, acogemos con gozo la invitación de Juan Pablo II: "¡Rema mar adentro!" (Lc 5,4). El Espíritu Santo llama a los presbíteros a una constante conversión para dar nueva fuerza, mayor claridad espiritual a su vida y a su ministerio. Los sacerdotes han de hacer suya la exhortación de San Pablo: "Cristo os ha enseñado a abandonar el anterior modo de vivir, el hombre viejo corrompido por deseos de placer, a renovaros en la mente y en el espíritu. Dejad que el Espíritu renueve vuestra mentalidad, y vestíos de la nueva condición humana, creada a imagen de Dios: justicia y santidad verdaderas" (Ef 4,20-24).

2 "El Señor Jesús enseñó a sus discípulos a cuidar con ejemplaridad de su propia vida, porque había de ser mirada constantemente por todos, como ciudad colocada sobre un monte, como luz que está colocada y luce sobre un candelero" (San Juan Crisóstomo, comentario a Mt 5, 14-16).

${ }^{3}$ S. Juan de Ávila decía que los sacerdotes caminarán bien orientados si mantienen su rumbo dentro de dos coordenadas: la santidad y la formación: "los eclesiásticos sean tales que more en ellos la gracia de la virtud de Jesucristo; lo cual alcanzado, fácilmente cumplirán lo mandado; y aun hará más por amor que la ley manda por fuerza" (Memorial $1^{\circ}$ al Concilio de Trento).

${ }^{4} \mathrm{~K}$, Rahner afirmó que "el sacerdote del mañana será místico o no será". Esto quiere decir que sin la experiencia religiosa interior de Dios ningún hombre puede permanecer siendo cristiano a la larga bajo la presión del ambiente actual secularizado. Todo ello supone que el sacerdote ha de hacer esa experiencia personal e íntima de Dios, sin la cual queda reducido a mero profesional de un culto mágico, que celebra los ritos de manera no creíble". Pide además que los sacerdotes del siglo XXI sean solidarios. 


\section{Los Presbíteros son llamados a la santidad}

\subsection{La llamada universal a la santidad}

Dios llama a todos los hombres a la santidad (cf. 1 Tes 4,3-7), por eso "nos eligió en su Hijo Jesucristo para que fuéramos santos e irreprochables en su presencia" (Ef 1,4).

El Concilio Vaticano II enseña que "todos los fieles de cualquier estado o condición, están llamados a la plenitud de la vida cristiana y a la perfección de la caridad" (LG 40). Por eso, la santidad no está reservada a un grupo o élite dentro de la Iglesia, ni es el resultado de una iniciativa del ser humano, sino que es un llamamiento amoroso y gratuito de Dios dirigido al hombre para que alcance la plenitud de la vida en Éls.

La llamada a la santidad implica como una realidad básica la incitación a la conversión, la vuelta del hombre a Dios ${ }^{6}$.

Este anuncio de la universalidad de la llamada a la santidad exige la comprensión de la existencia cristiana como "sequela Christi", como conformación con Cristo; no se trata de encarnar de modo extrínseco comportamientos éticos, sino de dejarse envolver personalmente en el acontecimiento de la gracia de Cristo. Este conformarse con Cristo es la sustancia de la santificación, y constituye la finalidad específica de la existencia cristiana. Para alcanzarla, todo cristiano necesita la ayuda de la Iglesia".

Hablar de la santidad y exhortar a ser santos hoy parece a algunos contemporáneos nuestros una evasión espiritualista dado que existen urgencias, necesidades y problemas humanos y sociales que deberían ser prioritarios. Podemos decirles que olvidan estos pensadores la enseñanza del Concilio Vaticano II: "la santidad promueve también en

5 "Los seguidores de Cristo, llamados por Dios no en razón de sus obras, sino en virtud del designio y gracia divinos y justificados en el Señor Jesús, han sido hechos por el bautismo, sacramento de la fe, verdaderos hijos de Dios y partícipes de la divina naturaleza y, por lo mismo, realmente santos" (LG 40).

6 "La vocación a la santidad es la invitación a la misma conversión del corazón y a participar de la vida de Dios uno y trino, lo cual significa y supera el cumplimiento de todos los deseos del hombre" (Sínodo de los Obispos, 1985). 
la sociedad terrena un estilo de vida más humano" (LG 40). Esta enseñanza es constante en la doctrina de la Iglesia ${ }^{7}$.

Juan Pablo II exhorta a todos y, en especial, a los jóvenes a no tener miedo a ser santos del tercer milenio y manifiesta que "surgirán nuevos santos si la familia sabe permanecer unida, como auténtico santuario del amor y de la vida; si las comunidades eclesiales mantienen su fidelidad al Evangelio"8.

Los Sacerdotes deben sentirse incluidos en esta llamada universal a la santidad ya que "en la consagración del bautismo, recibieron ya ciertamente, como todos los fieles cristianos, la señal y el don de tan gran vocación y gracia para sentirse capaces y obligados, en la misma debilidad humana, a seguir la perfección, según la palabra del Señor: sed perfectos como es perfecto vuestro Padre celestial" (PO 12; cf. LG 39)9.

Recordemos que "la santidad es un presupuesto fundamental y una condición insustituible para realizar la misión salvífica de la Iglesia, ya que es el secreto manantial y la medida infalible de su laboriosidad apostólica y de su ímpetu misionero" (ChFL 17) ${ }^{10}$.

Este debe ser el lema del Sacerdote: "quiero hacerme santo con los demás cristianos".

\subsection{La llamada común a la santidad se especifica en el sacerdote}

La vocación a la santidad del sacerdote tiene su primer fundamento en la consagración bautismal, como para todos los fieles (cf. PO

${ }^{7}$ El Sínodo de los Laicos dice: "La santidad de los laicos implica el servicio a la justicia y a la liberación de los pobres"

${ }^{8}$ La Conferencia Episcopal Española manifiesta que "la floración de santos ha sido siempre la mejor respuesta de la Iglesia a los tiempos difíciles, pues sólo una Iglesia de santos aparece nítidamente como fuente de esperanza para el mundo" Obispos Españoles: Plan pastoral, 2002).

${ }^{9}$ Mons. Julián López escribe: "La vocación del sacerdote a la santidad y, en consecuencia, el cultivo de la vida espiritual supone y requiere al mismo tiempo el crecimiento de la gracia bautismal con las virtudes y hábitos propios de quien es la vez bautizado y ministro de Cristo" (Mons. J. López).

${ }^{10} \mathrm{~S}$.Gregorio Nacianceno decía: "hay que comenzar purificándose a sí mismo antes de purificar a los demás; hay que instruirse para poder instruir; hay que hacerse luz para iluminar; hay que acercarse a Dios para acercar a los demás a Él; hay que hacerse santos para santificar". 
12). El carácter sacerdotal, comunicado por el sacramento del Orden, añade un nuevo título a esa vocación inicial.

1.3. ¿Cómo se especifica la llamada común a la santidad en el sacerdote?

A) La llamada específica del Sacerdote a la santidad nace del hecho de que el Sacerdote no sólo está en la Iglesia sino también está al frente de la Iglesia (cf. PDV 20). Los sacerdotes están especialmente obligados a tender a la santidad porque ellos -que han recibido una nueva consagración a Dios mediante la ordenación- son elevados a la condición de instrumentos vivos de Cristo, sumo y eterno Sacerdote, para proseguir en el tiempo su obra santificadora... "El sacerdote debe tender a la santidad por un nuevo motivo: corresponder a la nueva gracia que le ha conformado para representar a la persona de Cristo, Cabeza y Pastor, como instrumento vivo en la obra de la salvación (PO 12)

Este debe ser su lema: "me santifico por mis hermanos".

B) Los Sacerdotes son llamados a la santidad en virtud del Ministerio que realizan. Los presbíteros están ordenados a la santidad en virtud del ministerio, que ejercen en estrecha unión con el Obispo y entre sî" (PO 12).

Este debe ser su lema: "me santifico a causa del servicio pastoral".

C) Con la llamada de Dios para el ministerio presbiteral reciben también los sacerdotes, por el sacramento del Orden, una vocación específica a la santidad de vida que "queda caracterizada, plasmada y definida por aquellas actitudes y comportamientos que son propios de Jesucristo, Cabeza y Pastor de la Iglesia, y que se compendian en su caridad pastoral" (PDV 21). De esta forma están llamados a "prolongar la presencia de Cristo, único y supremo Pastor, siguiendo su estilo de vida y siendo como una transparencia suya en medio del rebaño que les ha sido confiado" (PDV 15).

Este debe ser su lema: "me santifico porque he sido consagrado al Señor". 
D) El ministro ordenado tiene su manera específica para vivir la caridad: se santifica viviendo la caridad en la forma pastoral. Desarrollaremos esto más adelante al hablar de la "caridad pastoral".

Ofrecemos unos textos que ayuden a reflexionar*.

\section{Respuesta de los Presbíteros a la llamada a la santidad}

Los sacerdotes han de responder con generosidad, prontitud y alegría a la llamada del Señor a la santidad por muchos motivos. Consignamos los siguientes:

- su fidelidad al Bautismo y al Sacramento del Orden que han recibido";

* "La plegaria de ordenación de los Presbíteros": "Te pedimos, Padre todopoderoso, que confieras a estos siervos tuyos la dignidad del Presbiterado; renueva en sus corazones el Espíritu de santidad, reciban de Ti el segundo grado del ministerio sacerdotal y sean, con su conducta, ejemplo de vida".

* El Concilio Vaticano II: "Los Presbíteros, ejerciendo el ministerio del Espíritu y de la justicia, se fortalecen en la vida del Espíritu, con tal que sean dóciles al Espíritu de Cristo, que los vivifica y conduce...Mas la santidad de los Presbíteros contribuye poderosamente al cumplimiento fructuoso del propio ministerio..." ("Presbyterorum Ordinis", n.12).

* Juan Pablo II manifiesta en esta misma línea lo siguiente: "nuestra fe nos revela la presencia operante del Espíritu Santo en nuestro ser, en nuestro actuar y en nuestro vivir, tal como lo ha configurado, capacitado y plasmado el sacramento del Orden. Ciertamente, el Espíritu del Señor es el gran protagonista de nuestra vida espiritual. Él crea el "corazón nuevo", lo anima y lo guía con la "ley nueva" de la caridad, de la caridad pastoral. Para el desarrollo de la vida espiritual es decisiva la certeza de que no faltará nunca al sacerdote la gracia del Espíritu Santo, como don totalmente gratuito y como mandato de responsabilidad" (PDV 33).

* San Juan de Ávila escribe: "si el Sacerdote quiere saber qué caudal de virtud ha de menester.. oiga a la santa Iglesia que...dice así: "los sacerdotes...serán santos para su Dios. Las cuales palabras tomó de lo que el Señor dijo a los sacerdotes de la vieja Ley: "seréis santos porque yo, vuestro Dios, soy santo". Las cuales palabras, si las oímos con fe y reverencia que les son debidas, y consideramos nuestra grande flaqueza, causarnos han gran confusión, viendo que nos es pedida santidad y por ventura aun no tenemos mediana bondad" (Tratado sobre el Sacerdocio, 5).

* Agostino Favalle dice: "Los presbíteros actúan más prontamente en su santificación gracias a la realización de su ministerio pastoral con tal que lo lleven a la práctica inspirándose en el ejemplo de Cristo, que tuvo como norma de su vida el cumplimiento de la voluntad del Padre y como criterio de su misión la total entrega al servicio de los hombres en las cosas que se refieren a Dios" ( "La dimensión misionera en los diversos sectores de la pastoral", en "La formación del sacerdote del tercer milenio", pp. 352ss. Arzobispado de Sevilla,1999). 
- la nueva evangelización debe hacerse con el fervor de los santos (Sínodo-85);

- ha de ser modelo espiritual y ético en nuestra sociedad.

\section{Documentos del Magisterio de la Iglesia en que se inspira este proyecto}

El texto de este Documento se fundamenta en la Constitución Dogmática "Lumen Gentium" y en el Decreto conciliar "Presbyterorum Ordinis"; y se inspira en el Documento "Guía pastoral para los Sacerdotes diocesanos de las Iglesias que dependen de la Congregación para la evangelización de los Pueblos" (Junio de 1989), en la Exhortación Apostólica Post-sinodal de Juan Pablo II: "Pastores dabo vobis" (1992), en el "Directorio para el ministerio y la vida de los Presbíteros" (Cong. para el Clero, 1994), en la Instrucción interdicasterial "Ecclesiae de mysterio" (1997), en la Carta circular "El presbítero, maestro de la palabra, ministro de los sacramentos y guía de la comunidad" (Cong. para el Clero, 1999), en la Carta Apostólica "Novo Millennio ineunte" (Juan Pablo II, 2001), en la Instrucción " el Presbítero, pastor y guía de la Comunidad Parroquial" (Cong. para el Clero, 2002), en la Carta Encíclica "Ecclesia de Eucharistia" (Juan Pablo II, 2003).

\section{4. ¿A quiénes está dirigido este Documento?}

Ofrecemos este documento a todos los Presbíteros como muestra de reconocimiento y gratitud por su generosa entrega al ministerio, como ayuda fraterna para vivir su específica espiritualidad y como aliento y estímulo para seguir realizando el ministerio pastoral que les ha sido confiado. Esperamos encontrar en los lectores una acogida benévola y fraterna. 


\section{CAPÍTULO PRIMERO: EL SACERDOTE DIOCESANO SECULAR}

\section{El Presbítero es un "hombre tomado de entre los hombres"}

"El sacerdote de hoy tiene que ser un hombre humano" (K. Rahner).

"¿Qué es el hombre"?, se pregunta el Concilio Vaticano II. Responder a esta pregunta no siempre resulta fácil pues hay que tener en cuenta que son posibles varias definiciones del ser humano teniendo en cuenta su estructura, su historia y su trascendencia ${ }^{1}$.

Veamos algunas descripciones del hombre.

"El hombre ni es simplemente finito ni simplemente infinito, sino el ser que, sabiéndose contingente, anhela una plenitud que escapa a sus posibilidades. La finitud del hombre está transida de infinitud. El Misterio está presente en el hondón de todo hombre" (Obispos Españoles: "Guía para la preparación espiritual" de la Visita Apostólica del Papa Juan Pablo II a España. Madrid 3-4 de Mayo de 2003).

El hombre es un ser creado por Dios "con quien se encuentra en una relación no de continuidad ontológica, ni de contradicción ontológica, sino en una relación de semejanza y de absoluta desemejanza, en una relación de autonomía y de radical heteronomía" (Mons. M. Ureña). Entre Dios y el hombre no existe "extrañeza ontológica" sino "entrañeza personal" (O. G. de Cardedal). "El hombre es una manera finita...de ser Dios real y efectivamente" (X. Zubiri).

Este hombre es referencia constitutiva a Dios; al tú, imagen de Dios; y al mundo, creación de Dios (cf. Gn 1.27). "Dios es el tú del hombre; el fondo último de lo humano es la apertura constitutiva, ineludible, inexorable a Dios... El hombre es el tú de Dios; cuando

${ }^{1}$ Olegario González de Cardedal: "tres definiciones del hombre: estructural que parte de las realidades físicas de un ser en cuanto son manifiestas o deducibles de su figura, acción o inserción en el medio; histórica que parte de la innovación radical que el hombre supone sobre las cosas; la voluntad, la libertad y la historia le son esenciales y, por ello, la posibilidad de forjar realidades nuevas no predeterminadas; teológica que presupone la histórica y hace del proyecto de salvación de Dios el punto de partida de la comprensión del hombre" ("La entraña del Cristianismo", pp. 831-833; Secretariado Trinitario; Salamanca; 1997). 
Dios mira al hombre, se encuentra reflejado en él" (J. L. Ruiz de la Peña). Por eso el hombre es, a la vez e indisolublemente "ser teologal, ser social y ser mundano". Y es todo eso ya en el orden de la Creación. Estas tres referencias constitutivas de lo humano son vividas por el hombre como sujeto responsable de ellas. Eso es lo que se significa cuando se afirma que el hombre es persona: tiene que responder de sí frente a Dios, frente al tú y frente al mundo. Por eso, y para eso, la persona es un ser libre.

El sacerdote, como todo hombre, tiene que vivenciar como propia la vocación religiosa humana, constitutiva de su ser como persona pues "en este designio eficaz de Dios está el fundamento de la dimensión constitutivamente religiosa del ser humano, intuida y reconocida también por la simple razón: el hombre está abierto a lo trascendente, a lo absoluto; posee un corazón que está inquieto hasta que no descanse en el Señor" (PDV 45). En definitiva, el hombre es la realidad imborrablemente anclada en la memoria divina ${ }^{2}$.

El hombre está abierto también al tú humano. El hombre libre es "el hombre para los demás". Ante el hombre siempre está presente la pregunta de Dios a Caín: “¿Dónde está tu hermano”? (Gn 4,9). Por ello hemos de tratar a los demás con profundo respeto, sin jamás manipularlos, ni instrumentalizarlos a nuestro servicio, ni convertirlos en un objeto de producción o de placer, en una cosa, en un nadie. Hemos de tratar a los demás como personas", como "prójimos".

\section{El Presbítero es un hombre bautizado}

Juan Pablo II muestra las maravillas que el Bautismo produce en el ser humano:

2 Olegario G. de Cardedal: "El sacerdote, como todo hombre, puede ser definido no sólo desde sus realidades esenciales sino también desde cada una de esas dimensiones estructuradoras de su existencia (existenciales): desde la capacidad de pensar y razonar (animal racional), desde la destinación a la muerte (Sein zum Tode), desde la voluntad de vida, desde el deseo de Dios, desde el rechazo del sin-sentido, desde la estructura psicosomática, desde la libertad frente al mundo, desde la destinación a la responsabilidad para con el prójimo y a la comunión con él, desde su necesidad de Absoluto, desde la llamada de Dios a participar en su misma vida". 
" nos regenera a la vida de los hijos de Dios; nos une a Jesucristo y a su Cuerpo que es la Iglesia; nos unge en el Espíritu Santo constituyéndonos en templos espirituales" (ChFL 10).

Refiriéndose al Presbítero, dice el Papa:

"El Bautismo caracteriza al presbítero como un "fiel" (Christifideles), como un "hermano entre hermanos", inserto y unido al Pueblo de Dios, con el gozo de compartir los dones de la salvación (cf. Ef 4,4-6) y en el esfuerzo común de caminar "según el Espíritu", siguiendo al único Maestro y Señor; un testigo de la resurrección de Cristo; comprometido a vivir el amor fraterno y la comunión, a dilatar el reino de Dios en el mundo y a madurar en la fe y en la libertad" (PDV).

\section{Consecuencias}

Los Sacerdotes, como todos los fieles cristianos, reciben por el Bautismo la vocación a la santidad. Como discípulo de Jesús, el sacerdote es llamado a la perfección según el modelo del Padre celestial (cf. Mt 5,48) en razón de la participación en el misterio pascual de Jesucristo como todos los bautizados y confirmados. Ahora bien, el sacerdote no ha de detenerse en su caminar hacia la santidad³.

\section{El Presbítero es un Sacerdote}

"El sacerdocio de los presbíteros se confiere por un sacramento peculiar por el que los presbíteros, por la unción del Espíritu Santo, quedan marcados con un carácter especial que los configura con Cristo Sacerdote, de tal forma que pueden obrar en nombre de Cristo Cabeza" (PO 2).

¿En qué consiste la identidad del sacerdote? La identidad del sacerdote es fruto de la acción sacramental del Espíritu Santo, participación de la acción salvífica de Cristo y se orienta plenamente al ser-

${ }^{3}$ F. J. Lorite escribe en esta dirección: "como oyente de la Palabra, como fiel discípulo de Cristo, como hombre de intimidad con el Señor, como hombre de Dios, como hombre de la caridad... Crecimiento exigido con mayor fuerza todavía en virtud de su ordenación sacerdotal". 
vicio de tal acción en la Iglesia, en su continuo desarrollo a lo largo de la historia. Se trata de una identidad tridimensional: pneumatológica, cristológica y eclesiológica.

Nos centramos en este momento en la dimensión cristológica de la identidad del Presbítero. Recordemos las enseñanzas de Juan Pablo II ${ }^{4}$.

Esta configuración ontológica con Cristo exige al Sacerdote que se configure existencialmente cada día más con Cristo hasta la identificación con Él de tal modo que cuando le oigan, oigan a Cristo; cuando le vean, vean a Cristo. Somos la presencia de Cristo Sacerdote y Pastor en la Iglesia. Por todo ello, el Sacerdote ha de tener un estilo de vida semejante al suyo: de inserción, revelación, oblación, resurrección, presidencia en la caridad, santificación, y ha de vivir el sacerdocio desde la consagración, la misión y la comunión eclesial.

Los presbíteros son sacerdotes "secundi meriti". Esta expresión significa que el Episcopado confiere la plenitud del sacramento del Orden y el Presbiterado es un ministerio de colaboración, sacramental y necesario, con los Obispos. Todos los servicios del presbítero llevan la marca de la leal colaboración con los obispos.

\section{El Presbítero es un sacerdote diocesano}

Los Presbíteros, por el sacramento del Orden, están consagrados al servicio de la Iglesia Particular (PO 10). Esta consagración es una entrega total, definitiva y exclusiva del Sacerdote e implica el amor, la fidelidad y el compromiso al servicio de esta Iglesia. Con todo, esta referencia a la Iglesia no es prioritaria en la definición de la identidad del Presbítero (cf. PDV 12). La conciencia de pertenencia a la Iglesia Local es uno de los elementos substanciales de la identidad y espiritualidad de un presbítero diocesano.

${ }^{4}$ Juan Pablo II recuerda en "Pastores dabo vobis" que el presbítero por el sacramento del Orden "ha quedado configurado con Cristo" (PDV nn.18,61); es "una representación sacramental de Jesucristo Cabeza y Pastor" (n.15); es su ministro (n.72); es imagen viva de Cristo Sacerdote (nn.12,43); es transparencia suya (nn.12,15); es su epifanía (n.49); personifica a Cristo (nn.15,19); es su embajador (n.16); su testigo (n.74); prolonga en la Iglesia y para la Iglesia la presencia de Cristo (n.60); es, al igual que Cristo, esposo de la Iglesia, testigo del amor de Cristo a él y a ella (n.22). 
Ahora bien, "la pertenencia y dedicación a una Iglesia Particular no circunscriben la actividad y la vida del presbítero, pues, dada la misma naturaleza de la Iglesia Particular y del ministerio sacerdotal, aquellas no pueden reducirse a estrechos límites" (PDV 32). ¿Cuál es la razón por la cual el sacerdote ha de abrirse a la universalidad de la Iglesia? Ciertamente hay una razón clara que podemos sintetizar de la siguiente manera: el ministerio del Sacerdote participa de la universalidad de la misión que Cristo entregó a los Apóstoles 5 .

El Presbítero queda incardinado a la Diócesis por su ordenación. La incardinación es un gesto de entrega de un hombre a su Iglesia Particular y, a la vez, es un gesto de acogida de ese hombre por la Iglesia Particular; además, no se agota en un vínculo puramente jurídico, sino que comporta una serie de actitudes y opciones espirituales y pastorales que contribuyen a dar una fisonomía específica a la figura vocacional del presbítero" (PDV 31).

Esta consagración, esta pertenencia y esta incardinación a la Iglesia Diocesana implican para el Sacerdote la diocesaneidad que se entiende como "misión eclesial orgánica" (Sínodo de 1971,13,6) y exige, por ello, sentirnos y sabernos responsables de la totalidad de la tarea del presbiterio diocesano, solidarios de la misión de la Iglesia Particular con los miembros de la vida consagrada y los laicos. Más adelante desentrañaremos su contenido al hablar de la relación del Presbítero con la Iglesia Particular.

Los sacerdotes religiosos, por pertenecer a un Instituto de perfección y de vida apostólica, están sujetos al Obispo diocesano en aquello que se refiere a la cura de almas, al ejercicio público del culto divino y a otras obras apostólicas. Pero en cuanto al carisma específico en el ejercicio del apostolado externo, dependen también de sus propios Superiores y deben permanecer fieles a la disciplina en su Instituto.

5 Juan Pablo II nos ofrece una respuesta lúcida: “el don espiritual que los presbíteros recibieron en la ordenación no los prepara a una misión limitada y restringida, sino a la misión universal y amplísima de salvación "hasta los confines de la tierra" pues cualquier ministerio sacerdotal participa de la misma amplitud universal de la misión confiada por Cristo a los Apóstoles" (PDV 32; cf. PO 10). La universalidad, es decir, la catolicidad, debe llenar con su propia sustancia la particularidad. 


\section{El Presbítero es un Sacerdote diocesano secular}

La relación del sacerdote con el mundo, su "secularidad", forma parte de su persona y de su ministerio, que es necesario y esencial para la Iglesia y saludable para la comunidad humana.

\section{¿De donde brota la secularidad del Presbitero?}

La secularidad del Presbítero brota de la radicación del ministerio en Cristo, el Hijo de Dios que se hace hombre y mundo, por lo que ya no es posible pensar al Dios de Jesucristo al margen del mundo y de la historia.

La secularidad del Presbítero brota también de la radicación del ministerio en la Iglesia ya que "tiene una dimensión auténticamente secular" (CLIM 25)6.

La Iglesia es sacramento universal de salvación para el mundo. Por eso, todo en la Iglesia está ordenado a su misión evangelizadora, cuyo destinatario es el mundo en el que "se ha de afrontar con valentía una situación que cada vez es más variada y comprometida, en el contexto de la globalización y de la nueva y cambiante situación de pueblos y culturas que la caracteriza" (NMI 40).

${ }^{6} \mathrm{~L}$. Trujillo, por su parte, afirma "esta secularidad no nace del sacramento del Orden, ni siquiera del Bautismo; es previa. El Bautismo la refiere a Cristo; el Orden la formaliza con nuevos matices existenciales" ("Relaciones propias del presbítero y su espiritualidad", en "Espiritualidad Sacerdotal", Congreso; Comisión Episcopal del Clero; 1989; pp.160171). 


\section{CAPÍTULO SEGUNDO: EL CARISMA Y EL MINISTERIO DE LOS PRESBÍTEROS}

\section{El Carisma Presbiteral}

El ministerio ordenado no es prioritariamente una función; prioritariamente es un carisma, una forma de existencia dada por el Espíritu en el sacramento del Orden, y que configura la vida de una persona. Es un carisma para la comunidad, pero que penetra y atraviesa el sujeto que lo recibe.

El presbiterado es un "carisma de totalidad" que no debe ser entendido como "una totalización de los carismas por parte del presbítero", sino en el sentido de que "es toda la vida del presbítero (y no sólo aquellos fragmentos y episodios de la misma requeridos por el ejercicio ministerial) la que queda asumida y marcada... La estructura del ministerio afecta de tal modo a la estructura de su servicio que requiere la dedicación de toda la persona" (Comis. Episcopal del Clero).

El carisma del ministerio ordenado contiene tal peso específico en el ser y quehacer del presbítero que todas sus relaciones quedan transformadas, de tal modo que su persona se pone al servicio incondicional de la comunidad y en ella de la humanidad. La gracia del carisma le modela de tal modo que todas sus relaciones quedan afectadas.

\section{El ministerio de los Presbíteros}

La Iglesia no existe para sí misma, sino para la misión; nace de las dos misiones: del Hijo y del Espíritu Santo. Surge esencialmente misionera.

Todos los cristianos tienen parte en la misión de Cristo porque el Señor Jesús hace partícipe a todo su Cuerpo Místico de la unción del Espíritu con que fue Él ungido.

El sacerdocio de los fieles y el sacerdocio ministerial son diferentes esencialmente y no solo en grado, aunque se ordenen el uno al otro, pues ambos participan a su manera del único sacerdocio de Cristo.

El presbítero debe encontrar su identidad dentro de una Iglesia misionera y ministerial, aportando lo específico suyo: obrar en la Per- 
sona de Cristo Cabeza, Sacerdote, Profeta y Pastor, haciéndole sacramentalmente presente en la comunidad ${ }^{1}$.

Por el sacramento del Orden los presbíteros reciben del Señor, por medio del Obispo, la misión de anunciar el Reino de Dios a todos los hombres y de santificar, presidir y cuidar al pueblo, a ellos encomendado, mediante el ministerio presbiteral de la palabra, de la santificación y el culto, y del gobierno pastoral en la caridad y en la comunión eclesial (cf. PO 4, 5, 6; PDV 26). Este ministerio no tiene su origen en la Comunidad; es don para la comunidad y procede de Cristo mismo, de la plenitud de su sacerdocio.

\subsection{Semblanza del ministerio de los Presbiteros}

El ministerio de los Presbíteros es un don y gracia que el Señor le concede y le regala. Por ello, el Presbítero ha de hacer suyas con toda verdad las palabras de Pablo: "por la gracia de Dios soy lo que soy" (1 Cor 15,10). Más aún, ha de realizar el ministerio recibido en conformidad con las palabras de Jesús: "lo que habéis recibido gratis, dadlo gratis" (Mt 10,8).

Dado que el presbítero participa según el grado propio de los presbíteros en la misión confiada por Cristo a los Apóstoles (cf. LG 28), su ministerio es apostólico: "entre los diversos carismas y servicios, únicamente el ministerio sacerdotal del NT, que continúa el ministerio de Cristo mediador y es distinto del sacerdocio común de los fieles por su esencia y no sólo por grado, es el que hace perenne la obra esencial de los apóstoles: proclamando eficazmente el Evangelio, reuniendo y guiando la comunidad, perdonando los pecados y sobre todo celebrando la Eucaristía, hace presente a Cristo, Cabeza de la Iglesia en el ejercicio de su obra de redención humana y de perfecta glorificación a Dios" (Sínodo 1971).

Es un ministerio evangelizador. "Los presbíteros tienen como deber primero el de anunciar a todos el Evangelio de Dios" (PO 4).

1 Mons. D. Ciriaco Benavente Mateos escribe: "No podemos olvidar que nuestro ministerio es principio estructurador de la comunidad cristiana, garantía en cada comunidad de identidad con la Iglesia apostólica" ("Discurso de apertura de la Asamblea Presbiteral de la Diócesis de Coria-Cáceres"). 
Esto no significa olvidar que todo discípulo de Jesucristo está llamado a cooperar en la acción evangelizadora de la Iglesia (cf. LG 35), antes bien el Presbítero ha de promover la participación consciente, activa y fraterna de los fieles laicos en la vida y misión de la Iglesia.

Es un ministerio de "comunión y colaboración responsable y necesaria con el ministerio del Obispo", en su solicitud por la Iglesia universal y por su Iglesia Particular, y con los demás presbíteros para hacer realidad la misión evangelizadora y pastoral de la Iglesia Particular (PO 2; 9). Recordemos siempre que no somos presbíteros, sino co-presbíteros; no somos apóstoles sino co-apóstoles; no somos operadores sino co-operadores; no estamos en misión, sino en co-misión. El ministerio de los presbíteros tiene una radical "forma comunitaria" y es ejercido como una tarea conjunta por la incorporación al orden de los presbíteros en comunión jerárquica con el Obispo (PDV 61). Esto no es una estrategia para ser eficaces, sino expresión de la comunión en un mismo sacramento recibido. La mejor forma para erradicar el individualismo es promover la colaboración que supone apertura, diálogo, tolerancia y generosidad para apoyar todo lo que hay de positivo en la vida y en el trabajo de los demás.

Es un ministerio espiritual ya que es realizado en el Espíritu Santo que enriquece a la Iglesia son sus dones, carismas y ministerios y hace eficaz toda acción ministerial. El dinamismo ministerial sin una sólida espiritualidad sacerdotal se traduciría en un activismo vacío y privado de valor profético 2 . Por ello, los presbíteros han de descubrir y agradecer la acción de Dios en su quehacer pastoral, ya que bien sabe que es el Señor quien hace fecundo su ministerio pastoral.

\subsection{Las tareas de este ministerio}

Este ministerio empieza por el anuncio de la Palabra, halla su momento más intenso en la celebración de la Eucaristía y continúa con la guía pastoral del Pueblo de Dios. Estas tres tareas son las tres dimensiones de un único e indivisible ministerio, están íntimamente

${ }^{2}$ La Sda. Congregación del Clero pone de relieve lo siguiente: manifiesta "Cualquier plan pastoral, cualquier proyecto misionero, cualquier dinamismo en la evangelización, que prescindiese del primado de la espiritualidad y del culto divino estaría destinado al fracaso" ("El Presbítero, pastor y guía de la Comunidad Parroquial", n.11). 
entrelazadas y encuentran su cumplimiento en la celebración eucarística. En otro lugar de este Proyecto se encuentran detalladas las funciones del Presbítero 3 .

\subsection{La finalidad de este ministerio}

La finalidad del ministerio ordenado consiste en "reunir y construir el Cuerpo de Cristo por la proclamación y la enseñanza de la Palabra de Dios, por la celebración de los sacramentos y de la Eucaristía y por la dirección de la vida de la comunidad en su liturgia, su misión y su diaconía" (cf. PO 4-6)4.

Los presbíteros exhortan y ayudan a los hombres a confesar que Jesús de Nazaret es el Mesías, el Señor, el Hijo de Dios y el Salvador, a entrar en comunión de amor y de vida con Él, a asumir como norma de conducta el camino de las Bienaventuranzas, a vivir esta fe en comunidad y a ser testigos del Señor en el mundo (cf. LG 35). Los Presbíteros ponen en este mundo los signos visibles del Reino de Dios que anticipan e iluminan el futuro reinado de Dios para que los hombres, reconciliados entre sí, puedan vivir en amor mutuo, en paz fraterna y en gozo común, a la espera de la bienaventuranza futura en el cielo ${ }^{5}$.

${ }^{3}$ Mons. D. Ciriaco Benavente afirma en este sentido lo siguiente: "Nuestro ministerio asegura las funciones básicas y necesarias que edifican, constituyen y desarrollan la comunidad: la palabra, el sacramento, la comunión y el servicio. Una buena espiritualidad no hipertrofia ni atrofia ninguna de ellas. El desarrollo unilateral hace presbíteros mutilados que acaban no sólo desvirtuando lo que omiten, sino también adulterando lo que subrayan" (ib.).

${ }^{4}$ Juan Pablo II enseña que "estamos llamados a contribuir, de varios modos, donde la Providencia nos pone, en la formación de la comunidad del Pueblo de Dios. Nuestra tarea consiste en apacentar la grey de Dios que se nos ha confiado, no por la fuerza, sino voluntariamente, no tiranizando, sino dando un testimonio ejemplar (cf. 1 Pe 5,2-3). Éste es para nosotros el camino de la santidad. Ésta es nuestra misión al servicio del pueblo cristiano" (Juan Pablo II: Homilía con ocasión del Jubileo de los Sacerdotes).

${ }^{5}$ La Sda. Congregación del Clero afirma en este sentido: "la tarea pastoral más relevante y fundamental del párroco, con diferencia, es conducir a los fieles hacia una sólida vida interior, sobre el fundamento de los principios de la doctrina cristiana, tal y como han sido vividos y enseñados por los santos" (Cong.del Clero: "El presbítero, pastor y guía de la comunidad parroquial", n.2). 


\section{CAPÍTULO TERCERO: CONTEXTUALIZACIÓN DE LA ESPIRITUALIDAD DEL SACERDOTE}

La contextualización en el espacio y en el tiempo de la espiritualidad sacerdotal es necesaria y esencial. No se puede hacer una presentación de la espiritualidad de forma desencarnada y a-histórica, ya que toda espiritualidad es una espiritualidad encarnada ${ }^{1}$. No se puede separar espiritualidad y vida. Por ello, el Sacerdote ha de conocer lo que pasa en sí mismo, en el mundo y en la Iglesia y por qué pasa; de este modo podrá dar una respuesta adecuada a los retos que surgen de la historia, de la cultura, del ambiente...

Junto a sus raíces teológicas, la espiritualidad sacerdotal ha descubierto también su radicación histórica. Se ha dado cuenta de que ha de responder a los auténticos requerimientos y retos que nacen del hombre, de la cultura, de la sociedad y de la Iglesia de nuestro tiempo. Los grandes rasgos que modelan a la comunidad humana y a la comunidad cristiana en una época determinada configuran, para bien o para mal, el ministerio y la espiritualidad del Sacerdote. Conocerlos, discernirlos y responder de forma adecuada a ellos es una tarea espiritual importante.

\section{Contexto existencial y biográfico}

La concreta espiritualidad del presbítero ha de estar en coherencia con su biografía ${ }^{2}$. La persona se va construyendo o malogrando a través de momentos existenciales importantes que influyen decisivamente en su espiritualidad. El desarrollo y la evolución física y psíquica del Presbítero acompaña a su espiritualidad a través de las distintas etapas de su existencia (cf. PDV 76-77).

Los primeros años del ministerio. Los Presbíteros jóvenes se entregan al ministerio con ardor e ilusión, con las ascuas encendidas

${ }^{1}$ Mons. D. Ciriaco Benavente Mateos: "la espiritualidad no es otra cosa que el dinamismo del Espíritu Santo animando y configurando la vida de un cristiano" ("Discurso de apertura de la Asamblea Presbiteral de la Diócesis de Coria-Cáceres).

2 Mons. Juan María Uriarte: "Crecer como personas para servir como pastores", en "La formación humana de los Sacerdotes según "Pastores dabo vobis" (Comisión Episcopal del Clero, pp.9-49). 
del Espíritu para anunciar a Jesucristo, para servir a los necesitados... Pero también se encuentran con situaciones que deben discernir y con problemas que debe resolver. Esto no es siempre fácil ya que a veces la realidad es tan fuerte que puede deteriorar su espiritualidad.

Los años de adulto. Los Presbíteros están en una situación de creatividad pastoral. Pero también pueden correr algunos riesgos como "un activismo exagerado, una cierta rutina en el ejercicio del ministerio, una cierta autocomplacencia e incluso un cierto cansancio interior peligroso" (PDV 77).

Los años de la senescencia. Los Presbíteros experimentan una estabilidad emocional y una profundización en la acción pastoral. Pero también pueden experimentar un progresivo despojo humano y pastoral.

El atardecer de la vida. Los Presbíteros viven esta etapa con serenidad de espíritu, con confianza... Pero también podrán experimentar la enfermedad grave, la soledad pastoral, la sensación de ser "in-útil" pues nadie solicita su servicio.

La hora de pasar de este mundo al Padre. Los Presbíteros viven esta etapa tan importante de su vida con la esperanza de "ver pronto al Señor a quien se consagraron, a quien sirvieron y en quien esperaron... Pero podrá también el Presbítero experimentar la tentación escatológica: apartarse del Señor, sumergirse en la duda, en el miedo...

\section{Contexto cultural}

\section{1. "Cambio de época"}

El transcurso del tiempo trae siempre consigo cambios nuevos en los diversos sectores de la vida humana. Vivimos hoy un situación tan peculiar que no es sólo una "época de cambios", sino que es un "cambio de época", "un cambio de tiempo eje" (Jaspers), un "periodo axial" (J. M. Vigil).

Ahora bien, a cada época histórica corresponde "una nueva experiencia de Dios", "una nueva espiritualidad". Por eso es necesario conocer los signos de "esta época nueva". 


\subsection{Las nuevas tecnologías}

Nuestra época se caracteriza por la comunicación, por el conocimiento, por la información -"demo" e "info"- Esto hace convierta nuestro mundo en "una aldea global" y transforma nuestra forma de ser. En efecto, no nos es fácil asimilar e integrar tanta y tan compleja información en la unidad de la persona. Por ello, con frecuencia nos sentimos más fragmentados, más enfrentados que en otros tiempos...

Por otra parte, en estos tiempos experimentamos la necesidad de una espiritualidad integradora, el deseo de una intimidad y de nuestra individualidad.

\subsection{La Globalización}

La globalización significa "el proceso de interconexión financiera, económica, política, social y cultural posibilitada por las Tecnologías de la Información y la Comunicación, que relaciona a determinadas personas y organizaciones gubernamentales o no, creando dinámicas complejas de relación y de exclusión" (Plan de Formación: la realidad del mundo. Acción Católica general de adultos).

Tiene rasgos positivos: el Espíritu Santo invita y mueve a unirse, integrarse, sumar esfuerzos y asumir compromisos al servicio de la paz, de la justicia, de la vida. Es la globalización de la solidaridad.

Tiene rasgos negativos ya que de alguna manera fomenta el desamparo, la miseria en no pocos, y hace hombres hedonistas, satisfechos, pragmáticos, individualistas, egoístas, consumidores; bloquea la espiritualidad de la solidaridad y del amor efectivo; tienta con un estilo de vida conformista y aleja de los pobres.

\subsection{La Interculturalidad}

Nuestras sociedades, antes uniformadas, se han convertido en sociedades multiculturales, multirraciales, multi-étnicas, multi-religiosas.

Esta interculturalidad hace surgir conflictos serios y, a veces, graves, que derivan de la incomprensión ante lo diferente. Además, las culturas dominantes y prepotentes tienen la tentación de aniquilar a las culturas más débiles. 
Esta interculturalidad plantea retos a la espiritualidad del Sacerdote y, al mismo tiempo, abre caminos para la evangelización, para la conversión y la purificación de la fe, para la creatividad al servicio de la misión bajo la guía del Espíritu Santo.

Optamos por una actitud de diálogo con las diversas religiones siguiendo las enseñanzas del Concilio Vaticano II: "La Iglesia Católica exhorta a sus hijos a que, con prudencia y caridad, mediante el diálogo y la colaboración con los seguidores de otras religiones, dando testimonio de fe y vida cristiana, reconozcan, guarden y promuevan aquellos bienes espirituales y morales, así como los valores socio-culturales, que se encuentran en ellos" (Nostra Aetate, 2; cf. Ib. n.3).

Juan Pablo II, por su parte, nos recuerda que "el diálogo debe continuar. En la situación de un marcado pluralismo cultural y religioso, tal como se va presentando en la sociedad del nuevo milenio, este diálogo es también importante para proponer una firme base de paz y alejar el espectro funesto de las guerras de religión que han bañado de sangre tantos períodos de la historia de la humanidad" (NMI 55).

\section{La situación cultural "postmoderna"}

La postmodernidad surge a partir del momento en que la humanidad comenzó a tener conciencia de que el proyecto de la Modernidad ya no era válido. Hablan de postmodernidad porque su tiempo ha aparecido después de la modernidad. No entenderíamos nada de la postmodernidad si no percibiéramos que está hecha de desencanto, desilusión, decepción.

Nos interesa conocer sus rasgos más característicos porque plantea algunas dificultades a la Espiritualidad del Sacerdote.

\subsection{Algunos rasgos peculiares de esta cultura}

"La fractura entre razón y fe": la razón moderna ha roto su religación constitutiva a la verdad real y ha dejado al hombre moderno sin verdad. Dicho de otro modo: el olvido del ser por la razón ha determinado que ésta se extraviara y dejara de dar su fruto natural: la verdad. Y allí en donde no hay verdad no puede habitar Cristo, que es la Verdad y la Vida del mundo (Mons. M. Ureña). El escepticismo desespe- 
ra de encontrar la verdad; no cree en ella. Tras esta tragedia desaparece cualquier posibilidad de descubrir lo eterno, lo inmutable, lo permanente...y, en consecuencia, lo Trascendente ${ }^{3}$.

Se busca lo práctico y lo rentable; lo demás, se dice, son teorías. Esto produce consecuencias muy importantes: el valor de las cosas se identifica con el beneficio que generan, la bondad de las cosas se mide por el placer que proporcionan, la felicidad depende de las cosas que se poseen... Se ha sustituido el ser por el tener.

El debilitamiento del pensar: "pensamiento débil" (Vattimo) o "light" (G.Lipovetsky) que trae como fruto una gran carga de retórica y simulacro. Es la "era del vacío". El "homo sapiens" ha sido desbancado por el "homo sentimentalis" que valora el sentimiento por encima de la razón. "Todos los pensamientos son malos pensamientos...El hombre no debe pensar" (F. Nietzsche). Esta cultura está de vuelta de las grandes visiones de conjunto, los grandes proyectos históricos, las utopías, las grandes metas. Se rechazan los "grandes relatos" de legitimación de lo verdadero y lo justo (J-H. Lyotard) y se refugian en los relatos pequeños y en el "fragmento".

El relativismo imperante hoy no admite la existencia de verdades absolutas, mantiene que la moral es relativa, plural y subjetiva y que el derecho es determinado por las leyes y el consenso social.

Un ambiguo retorno de lo religioso que se produce fuera de las Iglesias establecidas, una fascinación por lo misterioso, un cierto toque neo-oriental. Las creencias tienen origen en la propia subjetividad, por eso hay un cierto sincretismo e incluso politeísmo. En esa religiosidad pueden encontrarse mezclados elementos cristianos con elementos procedentes de otras religiones sin que preocupe la falta de coherencia del conjunto. Existen también las sectas, sobre todo las de inspiración oriental.

3 Conferencia Episcopal Española: "El hombre se ahoga así en su finitud" ("Guía para la preparación espiritual” ante la visita apostólica del Papa Juan Pablo II; Mayo, 2003). 


\subsection{Consecuencias:}

"Vivir una espiritualidad cristiana en semejante mundo no es algo que caiga de su peso, y mucho menos si se tiene en cuenta que el ambiente social no ayuda a poder y deber ser así, aun cuando un porcentaje muy alto de Padres pidan la educación religiosa para sus hijos, y éstos la reciban de hecho. Un teólogo del s. XX, H.U. v. Balthasar, decía en este sentido: "el cristiano mira en torno, desconcertado; se le ha desprendido algo que lo envolvía como un manto cálido y protector; y se siente desnudo. Se siente un fósil de edades pretéritas".

* En el ámbito moral y religioso:

La pérdida de los principios morales fundamentales. No pocos se mueven por lo que les gusta o les disgusta y, de este modo, la ética se convierte en "estética" y ésta en "dietética". No podemos saber qué es lo bueno y qué es lo malo. Todo lo más, podemos decir: "esto me parece bueno", o bien, "esto para mí es malo", pero sin tener la pretensión de que lo bueno y lo malo sea igualmente para todos. Se llega así a un relativismo moral, cuyos signos son la permisividad total y la indiferencia.

La cultura pública occidental moderna se aleja consciente y decididamente de la fe cristiana y camina hacia un "humanismo inmanentista", por eso presenta un rostro radicalmente arreligioso, en ocasiones anticristiano y con manifestaciones públicas en contra de la Iglesia...." (Mons. J. M. Uriarte).

"La ruptura entre Evangelio y la cultura" es el drama de nuestro tiempo" 4 ya que con esa ruptura han salido perdiendo la fe y la cultura. La fe, porque se ha quedado sin "la estructura de plausibilidad" (P. L. Berger) y la cultura, porque nuestro mundo se ha quedado sin ese "suplemento de alma" (Bergson) que tanto necesita. Se pretende privatizar la fe.

\footnotetext{
${ }^{4}$ Pablo VI: "Evangelii nuntiandi”, n.20.
} 
El rechazo de un Dios personal y trascendente, de un Dios encarnado y presente en la historia y en la humanidad. Esto ha sido llamado "crisis epocal". Martín Buber llama a esta crisis "eclipse de Dios", evocando al "Dios ha muerto" de Nietzsche. J. B. Metz la ha denominado "crisis de Dios" que repercute en la configuración de la persona humana moderna. Otros escritores hablan de la "falta de Dios" (M. Heidegger), del "ocultamiento de Dios" (J. Sudbrack), o de su "lejanía" (K. Rahner). "La palabra de Dios se ha convertido para muchos en un término vacío, que ya no afecta a la realidad en la que viven ni tiene sitio en su contexto experiencial. Dios no es reconocido como referente ni en el pensamiento, ni en la inspiración para la vida ni en la cultura de los medios para no pocos españoles. Por eso no es de extrañar que haya personas que hablen de "desmoronamiento del universo cristiano" (C. Imbert), de "era post-cristiana" (E. Poulat) y que se entronicen en los altares del mundo los ídolos y dioses de las mitologías que se adueñan del hombre: "desde que los hombres han dejado de creer en Dios, no es que no crean en nada; ahora creen en todo" (Chesterton).

Tras el materialismo práctico se esconde un rechazo de Dios y de toda Trascendencia, así como de las preguntas básicas sobre el sentido de la vida. Desde el materialismo dialéctico, pasando por el neopositivismo, el vitalismo y otras corrientes ateas de existencialismo, se ha pretendido dibujar una antropología donde el horizonte material aspira a saciar toda la sed del hombre. De estos temas ha hablado Juan Pablo II en dos Encíclicas: la "Veritatis Splendor" y la "Fides et Ratio".

El irracionalismo implica la negación de toda filosofía, de toda razón. Es lo propio de la cultura -pseudocultura- de la new age. Es el imperio del sentimiento irracional, de la disolución de la conciencia individual, de la aparición de formas pseudo-religiosas gnósticas. A este tema han dedicado recientemente un documento unos Organismos de la Santa Sede 5 .

Jesucristo no es aceptado como el fundamento de la verdad, sino como un sugestivo pensador que irremediablemente pertenece al pasa-

5 Consejo Pontificio de la Cultura y Consejo Pontificio para el Diálogo Interreligioso: "Jesucristo, portador del agua de la vida. Reflexión cristiana sobre "New Age", 2003. 
do. Por tanto, "no se puede reivindicar que el Verbo encarnado sea contemporáneo al hombre de todos los tiempos" (A. Scola).

* En el ámbito de la predicación de la Iglesia

La negación explícita o implícita de Dios favorece que sea difícil hoy hablar de Dios y de la trascendencia a un hombre que se acostumbra a pensar, vivir y actuar de espaldas a Dios, y "en un mundo que se va haciendo históricamente y en el que no encontramos las huellas de Dios sino las nuestras" (W. Kasper).

En una cultura dominada por el pensamiento débil, es difícil que se plantee "las últimas preguntas", con las que la fe puede dialogar, trascendiendo el nivel superficial de las modas, de los usos... Realmente este aspecto empobrece la espiritualidad dado que, por ejemplo, "el sentido de la vida" se pierde o se convierte en "un sentido más junto a otros", o "en pura invención humana".

El relativismo produce grandes dificultades al Sacerdote para llegar con su mensaje a la sociedad ya que presenta verdades absolutas e inmutables, habla de la verdad objetiva en la que se asienta una moral universalmente válida y de un derecho o derechos con base en la naturaleza humana....

\section{* En el ámbito de la antropología}

De una cultura teocéntrica hemos pasado a una cultura antropocéntrica. El hombre liberado de toda tutela religiosa, se convierte en la norma y medida de todo... Este mismo hombre, creyéndose libre de Dios, como el hijo pródigo, a menudo se hace esclavo de ídolos de muerte: el tener, el poder, el disfrute a cualquier precio y el egoísmo radical (cf. CLIM 137).

El individuo de hoy no es un yo integrado, sino que " compone a la carta" los elementos de su existencia, tomando unas ideas de acá y otras de allá, sin preocuparse demasiado por la mayor o menor coherencia del conjunto ya que no tiene certezas absolutas, y sus opiniones son susceptibles de modificaciones rápidas" (L. G. de Carvajal). 
La grave crisis del hombre. El rechazo de Dios genera la quiebra interior del hombre, difumina el sentido de las profundas aspiraciones humanas, debilita y deforma los valores éticos, favorece la instalación del ser humano en la finitud absolutizada y hace perder la conciencia de la identidad personal. Y entonces todo pasa a ser provisional . El olvido de Dios no hace al hombre más libre, sino más "roto", más "fragmentado", más "desorientado".

La postmodernidad tiene también efectos positivos ya que nos hace recuperar valores ignorados por la Modernidad:

- la experiencia religiosa que lleva consigo la conversión y la oración;

- una teología que no maltrate al misterio;

- un cristianismo festivo;

- la subjetividad, la libertad, la igualdad, el sueño lúdico;

- la sintonía con el cosmos y la vida, el diario cantar de las aguas próximas...

Optamos por el diálogo con la cultura actual: "La Iglesia es hoy consciente de la necesidad de contribuir a la promoción de la cultura y al diálogo entre cultura y fe" (VC 98-99), desde una actitud dialogante y crítica inspirada en el Evangelio.

\section{3. ¿Qué necesitan el hombre y la mujer de hoy?}

a) Necesidad de sentido: hoy se cuida mucho lo inmediato y se olvida el horizonte último. Sin embargo los grandes interrogantes del ser humano permanecen: ¿por qué vivimos? ¿qué buscamos? ¿cuál es nuestro destino final? Nuestra acción pastoral ha de aportar sentido al hombre de hoy.

b) Necesidad de gracia: hoy se mira casi de forma exclusiva a la eficacia y el rendimiento, llenando la vida de confort, de bienestar... Pero ¿basta el pragmatismo, el disfrute de lo inmediato, la rentabilidad económica? Hemos de hacer presente la gracia de Dios, ampliar el horizonte de la existencia y ayudar al hombre a abrirse a la gratuidad de la salvación de Dios. 
c) Necesidad de reconciliación: el hombre y la mujer de hoy viven con alguna frecuencia no reconciliados con Dios, consigo mismos, con el mundo, con los demás, con la naturaleza. ¿No necesita el hombre y la mujer vivir reconciliados en todos los niveles antes citados? Nuestra misión ha de promover la reconciliación personal, matrimonial, familiar y social.

d) Necesidad de liberación del pecado. Tenemos conciencia de nuestros pecados, faltas...Pero buscamos con cierta facilidad la autojustificación atribuyendo nuestra culpa a otro, a las estructuras, al pasado. Nuestra misión ha de anunciar y dar testimonio del perdón y de la salvación que se nos ofrece en Jesucristo.

e) Necesidad de esperanza. Las utopías se han desmoronado, el desencanto y el malestar han hecho su aparición; con todo, el ser humano sigue anhelando plenitud. Hay crisis de esperanza; pero ¿dónde encontrar y cómo recuperar la esperanza? Nuestra misión nos ha de llevar a "dar esperanza, a transmitir esperanza".

f) Necesidad de salvación. Por mucho que algunos se empeñen que el hombre no necesita ser salvado por nadie; todos sabemos que el ser humano en lo más profundo de su corazón anhela y desea ser salvado de tantas situaciones límites a las que él no puede hacer frente. Nuestra misión consiste en ayudar al hombre y a la mujer a descubrir esa necesidad de ser salvado y a ofrecerle a Jesucristo, el Salvador de la humanidad. ¿Seremos capaces de hacerlo? Evangelizar es responder a estas necesidades.

\section{Contexto social}

Los grandes rasgos que modelan a la comunidad humana en una época determinada configuran, para bien o para mal, el ministerio y la espiritualidad el Sacerdote. Conocerlos, discernirlos y responder adecuadamente a ellos es una tarea espiritual importante y necesaria. 


\section{Semblanza de la sociedad actual}

No pretendemos describir nuestra sociedad. Nos limitamos a ofrecer unos aspectos para acercarnos a su conocimiento.

Aspectos positivos que brotan de la conciencia moral actual:

- la defensa de la dignidad del ser humano y de sus derechos humanos,

- el pluralismo, la tolerancia y la repulsa de las desigualdades,

- el cuidado de la creación y el respeto de la naturaleza,

- la pregunta sobre el sentido, es decir, sobre una escala objetiva de valores que permita establecer las posibilidades y los límites del progreso,

- la aspiración universal a la paz y al entendimiento entre todos,

- el rechazo de toda forma de violencia y discriminación,

- el auge del voluntariado, las ONGS, la solidaridad.

\section{Signos preocupantes}

La insolidaridad. Nuestra sociedad está injustamente "dualizada": entre un tercio de pobres perdedores y dos tercios ganadores, más o menos ricos. Quitar a Dios como referente de la vida fraterna, como Padre que hace hermanos a los hijos, que le reconocen y aman, lleva consigo la indiferencia, la injusticia y la explotación de unos hombres por otros. Son tiempos "de pasión" porque muchos seres humanos son perseguidos, masacrados, mueren de hambre. Estamos viviendo una etapa muy dura de la historia humana.

La búsqueda del bienestar: "en el mundo de los hombres, el goce es el alfa y la omega, el principio y el fin" (E. Guisán). Se busca aque110 que satisface y no pide esfuerzos. Dado que no puede cambiar la sociedad, pretende disfrutar al menos del presente con una actitud hedonista que recuerda el "carpe diem". Por ello, hay una creciente valoración del placer, del cuerpo, del hedonismo, del consumismo...

La primacía de la información sobre la formación ya que lo que cuenta es la rapidez de los procesos. Esto lleva consigo un cierto gusto 
por lo efímero, por "la levedad del ser" (M. Kundera). La sociedad actual es la sociedad de la comunicación, de la información producida por las nuevas tecnologías. Esto afecta a nuestro modo de ser. Vivimos en una red amplísima de relaciones.

Las corrientes que conviven en el seno de la sociedad son, al menos, cuatro: "la utopía social, con la paradoja de una fuerte carga de agnosticismo e increencia; la postmodernidad, en sus tres versiones de nihilismo o desencanto, de resistencia y de neoconservadurismo; el funcionalismo y lo neoconservador (R. Berzosa).

La persistencia de la violencia, del terrorismo, de la guerra, del hambre.

\section{2. ¿Cómo influye esta sociedad en la espiritualidad del Presbítero?}

El "pensamiento único" que hace inviable todo cambio o alternativa y el "final de la historia" con la consiguiente desesperanza en la transformación social y liberación de los pobres, están en clara oposición con la espiritualidad del Sacerdote que está siempre en proceso de renovación, profundización...

Una sociedad injustamente estructurada en buena parte no acepta con facilidad una evangelización que le exige un cambio y un orden nuevo y le reclama la atención a los pobres y la defensa de los derechos humanos. Una espiritualidad sacerdotal que no sea evangelizadora no es auténtica.

Una sociedad secularizada y fragmentada produce y causa la pérdida de la identidad social por parte del Sacerdote en la sociedad. Nuestra espiritualidad no es algo amorfo, anónimo... tiene identidad propia y específica.

Por todo ello, hemos de situarnos de manera correcta en nuestra sociedad pluralista y democrática, laica y secularizada. Tenemos que amar este mundo porque es el mundo de Dios; tenemos que seguir apostando por la esperanza porque sabemos que Jesucristo ha vencido el pecado y la muerte y nos ha dado el Espíritu Santo para que nos sostenga; tenemos que seguir creyendo en el hombre y en su apertura al 
Evangelio porque creemos en el Dios que nos ha creado y que se ha encarnado en Jesucristo (cf. GS 1).

\section{Contexto eclesial}

El Sacerdote ha de conocer la Iglesia ya que los grandes rasgos que la modelan en una época determinada configuran su ministerio y su espiritualidad. Por su parte, el Presbítero ha de detectar las llamadas que Dios le hace a través de la Comunidad Cristiana y responder a ellas.

\section{Realidades positivas y preocupantes en la Iglesia actual}

\subsection{Realidades eclesiales positivas}

La fidelidad de muchos cristianos a su vocación bautismal y el compromiso público y privado de la fe en un contexto cultural difícil y la vida santa, entregada, austera y ejemplar de muchos sacerdotes y personas consagradas y el testimonio evangélico de muchos misioneros y misioneras.

La purificación de las actitudes religiosas y de la experiencia de Dios y la incorporación de los Laicos y de los Religiosos a la Iglesia.

La vitalidad renovada de movimientos apostólicos y comunidades cristianas, de la Catequesis y de la enseñanza de la Religión en las Escuelas y Colegios y la renovación de los ámbitos de comunión y de corresponsabilidad en las Parroquias.

La sensibilidad de muchos católicos para ayudar a las Misiones y a los Pueblos más pobres y necesitados y para defender los derechos humanos y el espléndido testimonio del martirio que dan hoy muchos cristianos. 


\subsection{Realidades preocupantes en la Iglesia en España}

La débil transmisión de la fe o la interrupción de la transmisión de kerigma a las generaciones jóvenes. Muchos crecen y viven sin haber recibido noticia alguna de Jesucristo. Por otra parte, la Iglesia experimenta hoy serias dificultades para hacer llegar e insertar su mensaje en la Sociedad, sobre todo en la juventud.

La disminución de las vocaciones para el sacerdocio ministerial, para la vida de especial consagración, tanto religiosa como secular, y para la existencia cristiana que deriva del sacerdocio común de los fieles.

El envejecimiento del clero, que inevitablemente repercute en una creciente distancia entre educadores y educandos.

El abandono de la fe y de la Iglesia. No pocos desertan del culto o acuden a él en contadas ocasiones. Tienen un sistema de creencias seriamente erosionadas en relación con el conjunto del credo cristiano y disminuye la intensidad de su adhesión. Se han alejado abiertamente de la pertenencia a la Iglesia y confían escasamente en ella.

La desconfianza hacia el Magisterio jerárquico. La Iglesia sufre dentro de ella misma el disenso doctrinal protagonizado por algunos teólogos y maestros...'Ha venido a crearse una nueva situación dentro de la misma comunidad cristiana, en la que se difunden muchas dudas y objeciones de orden humano y psicológico, social y cultural, religioso e incluso específicamente teológico, sobre las enseñanzas morales de la Iglesia..." (Veritatis splendor, 4).

Primacía de lo cultual sobre lo pastoral. A veces se valora más el trabajo cultual que el pastoral, porque eso es lo que piden y solicitan los fieles. Se conocen los fallos en la acción pastoral, pero se tarda en poner en remedio.

Poco protagonismo de los laicos. En un mundo secular parece necesario que los laicos habrían de realizar un papel más importante en 
Ia vida y misión de la lglesia. Sigue siendo realidad el clericalismo en la Iglesia.

Poca presencia de los laicos cristianos en la secularidad, como les ha pedido el Concilio Vaticano II.

\subsection{Realidades preocupantes en no pocas diócesis}

May una gran mayoría que están bautizados y se autodefinen católicos, aunque las cifras bajan sensiblemente si nos referimos a los jóvenes.

Existe una considerable distancia entre la simple afiliación y la práctica religiosa o el seguimiento de las pautas de comportamiento que ella señala. Muchos bautizados no se sienten obligados a asistir a la Misa dominical, no comparten las orientaciones de la Iglesia en el campo de las creencias o la moral o, incluso, proclaman abiertamente su alejamiento de los ámbitos eclesiales" (Plan pastoral diocesano, I; p.6).

No pocos se sienten acomplejados como cristianos ante la preponderancia de la Sociedad actual y ante los poderes políticos, económicos, culturales. El Cristianismo es aceptado en cuanto "abierto" a los principios de la cultura pública, es decir, a su disolución como fe religiosa y a su integración en la cosmovisión inmanentista dominante.

\section{2. ¿Cómo considera la Sociedad actual a la Iglesia?}

\subsection{Una Iglesia "cuestionada" en la Sociedad}

"¿Por qué la Iglesia le resulta desagradable a tanta gente, incluso también creyentes, e incluso a personas que hasta ayer podían contarse entre los más fieles." ( $J$.Ratzinger).

La Iglesia está cuestionada por aquellos que:

- La invitan o la empujan a recluirse en sus espacios religiosos y a ofrecer sus servicios sociales a los pobres, desvalidos, marginados;

- le niegan o discuten el derecho a decir una palabra sobre temas sociales, humanos... considerando esa palabra como una injerencia política... 
- Ia descalifican como "una reliquia del pasado", a la que hay que reducirla al silencio cuando no se acomoda a la doctrina del "pensamiento úmico", de 10 "políticamente correcto", de la opinión de las mayorías o de lo que la moda, los MCS... imponen como lo único verdadero, bueno $u$ opinable.

\subsection{Una Iglesia "minorizada" en una Sociedad poderosa}

Las grandes corrientes que configuran y educan la mentalidad, la sensibilidad, las actitudes y los comportamientos de la gente vienen cada vez menos de emisores eclesiales y cada vez más de instancias seculares. Esto es lo que significa una "Iglesia minorizada", "no minoritaria". La Iglesia en España configura cada vez menos la atmósfera espiritual, el clima de la sociedad.

¿Esta "minoridad" está suscitando una presencia más evangélica de la Iglesia en la sociedad?

\section{La situación actual de la Iglesia y la espiritualidad del Presbítero}

Así como el ejercicio del ministerio y la vida del Presbítero influyen en la Iglesia, también la situación eclesial influye en la espiritualidad del Presbítero. Fijémonos en este aspecto.

La escasez de sacerdotes lleva al Sacerdote a realizar muchas actividades hasta el punto de que su vida esté expuesta a un creciente "activismo externo", sometiéndolo a un ritmo a veces frenético y desolador, que ni es bueno para su espiritualidad ni es provechoso para la Comunidad Cristiana.

La caridad pastoral corre el riesgo de ser vaciada de su significado por un cierto "funcionalismo" que reduce el sacerdocio ministerial a los aspectos funcionales, con lo que el ejercicio de su ministerio pastoral deja de ser fuente de espiritualidad pues se resiente y se mecaniza.

La falta de respuesta personal y comunitaria de no pocos cristianos a las nuevas propuestas pastorales puede llevar al sacerdote al desánimo, a la decepción y a la desesperanza. 


\section{CAPÍTULO CUARTO: LA ESPIRITUALIDAD DEL SACERDOTE DIOCESANO SECULAR}

Nuestra intención no es sólo presentar los contenidos básicos de la espiritualidad sino también ir dando respuesta a los retos y dificultades que la historia, la cultura, la sociedad, la Iglesia, la biografía del Presbítero plantean a la espiritualidad del Sacerdote

\section{Visiones incorrectas de la espiritualidad cristiana}

Hoy se habla mucho de "espiritualidad" y se constata "una difusa exigencia de espiritualidad". No es el momento para exponer con detalle las diversas concepciones de la espiritualidad. Con todo, queremos poner de relieve algunas concepciones incorrectas de la espiritualidad cristiana.

* Algunos reducen la espiritualidad a lo intelectual, a prácticas piadosas, a la "vida del alma", a conceptos meramente humanistas y políticos o a una actuación sociopolítica.

* Otros entienden la espiritualidad como "lo no-material, lo nocorporal, lo no-social, lo ahistórico".

* Otros la identifican con meras devociones, oraciones..., o la confinan en la interioridad de la persona.

A modo de respuesta:

La formación y la vivencia de la espiritualidad ha de evitar las actitudes y prácticas dualistas, las evasiones espiritualistas y desencarnadas, la dispersión por el activismo, la reducción al funcionalismo, la superficialidad, el vacío o la pérdida de sentido, cualquier tipo de parcialización de la fe por su sometimiento a intereses o ideologías (cf. PDV 72), las llamadas prácticas piadosas y el ámbito exterior del puro compromiso por la transformación del mundo y de sus estructuras sociales. 


\section{La Espiritualidad Cristiana}

\section{1. ¿En qué consiste la espiritualidad cristiana?}

El Bautismo es el manantial de la espiritualidad cristiana, que consiste en "el proceso personal y comunitario de seguimiento e identificación con Cristo Jesús, como respuesta al designio y vocación que Dios ha dirigido a cada uno de los miembros de su Pueblo, y que Pablo presenta así: "Dios nos ha elegido en Cristo Jesús para ser santos y para ser sus hijos adoptivos por medio de Jesucristo" (Ef.1,4-5).

Juan Pablo II describe la espiritualidad como "vida animada y dirigida por el Espíritu hacia la santidad o perfección de la caridad" (PDV 19).

La vida espiritual es la vida suscitada y comunicada por el Espíritu de Dios; es la vida según el Espíritu Santo. Por eso, la espiritualidad es don de Dios al hombre: la espiritualidad cristiana es don más que conquista; es gracia de Dios más que obra del hombre; es gratuidad más que esfuerzo; es dejarse modelar por el Señor antes que hechura de nuestras manos.

\subsection{Características de la espiritualidad cristiana}

El Concilio Vaticano II describe la espiritualidad con estos rasgos: "espiritualidad litúrgica, espiritualidad bíblica y cristocéntrica, espiritualidad en medio del mundo, espiritualidad eclesial-comunitaria, espiritualidad ecuménica, espiritualidad misionera".

Teniendo en cuenta estas enseñanzas conciliares, la espiritualidad cristiana se caracteriza por estos rasgos principales:

- Bautismal: la espiritualidad cristiana, encarnada en cada ser humano, en cada comunidad, tiene para todos y siempre un denominador común: el bautismo. Toda espiritualidad cristiana es bautismal; radica, por tanto, en el misterio pascual de Cristo al que se incorpora el hombre por el sacramento del Bautismo.

- Teologal ya que es una espiritualidad centrada en la fe que vence al mundo (cf. 1 Jn 5,4), en la esperanza que se afirma incluso 
contra toda esperanza (cf. Rm 4,18) y en el amor a Dios que se historifica en solidaridad activa con los necesitados (cf. Mt 25,34-40).

- Trinitaria ya que brota del seguimiento de Jesús, movidos y guiados por el Espíritu Santo, caminando en relación filial como hijos del Padre y con la esperanza de un encuentro definitivo y eterno con Él.

- Eclesial: La espiritualidad cristiana será vivida en la Iglesia, se recibirá de ella, se dará a ella y colaborará con ella. Por eso, implica siempre una referencia a la Iglesia del Señor. Nunca es individualista, sino comunional ya que todos formamos un solo cuerpo, somos movidos por un mismo Espíritu y somos enviados a realizar una misma misión: anunciar con obras y palabras el Reino, el evangelio de Jesús, a Jesucristo.

- Radicalmente evangélica. La espiritualidad cristiana se entiende como la forma concreta de vivir el Evangelio, vinculada al seguimiento de Jesús y al encuentro con Él. Hemos de identificarnos con las actitudes y los valores que Jesús encarnó y vivió en las circunstancias de su tiempo y que nosotros debemos encarnar en las de nuestra época. Pero siempre en comunión de vida con el Cristo post-pascual.

- Abarca la totalidad de la persona: la espiritualidad afecta a la persona humana en su relación con Dios y con el mensaje de Jesús, con el mundo, con la sociedad, con los hombres. Unifica la vida del cristiano, ayudando a superar tensiones, dualismos: la oración y el compromiso al servicio del mundo, la contemplación y la acción; la trascendencia y la inmanencia, la Iglesia y el mundo; el yo y la comunidad; la relación con Dios y la fraternidad humana...1.

- Encarnada². La espiritualidad cristiana es una espiritualidad de inserción en el mundo. Toca de lleno la trama de la historia humana

1 J. Lois: "la articulación feliz entre mística y política, contemplación y acción liberadora, vida y celebración, gratuidad y eficacia. Tal vez podría decirse sin exagerar que en el logro de esa articulación radica la credibilidad y más decisiva significación de la espiritualidad cristiana en el momento actual" ("Jesús de Nazaret, el Cristo Liberador", p.193; Edic. HOAC).

2 Concilio Vaticano II: “Apostolicam Actuositatem”, n.32). 
desde el lugar en que se situó el Dios pobre, humillado y sacrificado. Es querer vivir la experiencia y el destino del crucificado en la lucha por la salvación de los pobres, de los humillados y sacrificados. Es apertura a los valores humanos en la justa perspectiva de la "Gaudium et Spes" y en la sana coherencia de la antropología cristiana. La espiritualidad cristiana es de acción y de compromiso ${ }^{3}$. En fidelidad a las enseñanzas de la Iglesia y en respuesta a los problemas humanos existentes la Iglesia en Extremadura ha estudiado el problema de la Pobreza en estas tierras ${ }^{4}$.

- En tensión escatológica permanente. La espiritualidad cristiana sitúa al cristiano en una constante renovación y conversión, abierto permanentemente a la apremiante llamada de Dios y alejado de toda tentación de acomodación o instalación definitiva ya que "somos ya hijos de Dios pero aún no se ha revelado la gloria de los hijos de Dios en su plenitud". Esperamos "los cielos nuevos y la tierra nueva".

\section{Distintas espiritualidades}

La espiritualidad que surge del sacramento del bautismo adquiere conformaciones especiales y distintas en cada uno de los carismas y ministerios de la Iglesia (K. Rahner), dado que no hay una sola forma histórica de expresar y hacer presente la riqueza de la vida de Dios en Jesús ni el ímpetu renovador y creador del Espíritu de Cristo ${ }^{5}$. Cada

3 Juan Pablo II nos enseña: "esta vertiente ético-social se propone como una dimensión imprescindible del testimonio cristiano. Se debe rechazar la tentación de una espiritualidad oculta e individualista, que poco tiene que ver con las exigencias de la caridad, con la lógica de la Encarnación y,en definitiva, con la misma tensión escatológica del cristianismo" (SRS 14).

${ }^{4}$ La Iglesia en Extremadura ante la pobreza: "La verdadera espritualidad no deja de lado las cosas materiales, las personas en donde se encuentra preferentemenbte con Jesús. Con ese Jesús que está en el necesitado. La espiritualidad une de un solo golpe el amor de Dios y el amor al prójimo. El "mundo material y el mundo espiritual" ( Sector de trabajo: "Espiritualidad y experiencia de Dios desde los pobres", pp.297-305).

5 I. Ellacurría escribe a este respecto: "Los cambios históricos, las nuevas demandas, la presencia de hombres llenos del Espíritu han enriquecido a lo largo de la historia la espiritualidad cristiana con nuevas lecturas de la persona y el mensaje de Jesús ("Espiritualidad", en "Conceptos fundamentales de Teología Pastoral, pág.304). 
una de las espiritualidad pondrá de relieve aspectos específicos: "Cada una de las espiritualidades acentúa una dimensión del misterio de Dios y reclama una acentuación de la vida personal con la correspondiente exigencia moral, forma de integración en la Iglesia y de implantación en el mundo".

Dentro de estas diversas espiritualidades se encuentra la "específica espiritualidad del Sacerdote diocesano secular". A partir de ahora vamos a centrar nuestra atención en ella.

(Continúa en el número siguiente) 